\title{
Assessment of manual load carrying and health status of women farm workers of district Sonipat (Haryana), India
}

\author{
S. Jena*, A. Kumar and J. K. Singh \\ Division of Agricultural Engineering, Indian Agricultural Research Institute, New Delhi-110012, INDIA \\ *Corresponding author. E-mail : swagatika.jena@gmail.com \\ Received: December 27, 2014; Revised received: March 12, 2015; Accepted: April 9, 2015
}

\begin{abstract}
In present study an assessment of manual load carrying and health status of women farm workers of Thana Kalan village, Kharkhoda tehsil in Sonipat district of Haryana was conducted. A total of forty women farm workers between 25-40 years age were selected with at least five year load carrying experience, involved in farm work, with no history of chronic disease and willingness to participate in the study. The women farm workers carried water, fodder, cow dung on daily basis and seed, fertilizer and other farm inputs and farm produce on seasonal basis. It was observed that preferable mode of load carrying was head. The quantum of load varied between 20-40 $\mathrm{kg}$. Assessment of health status revealed that musculoskeletal disorder was prevalent in all the age groups. Musculoskeletal disorder namely lower back pain was observed in 87.5 per cent women workers, neck pain in 72.5 per cent women workers followed by knee $(32.5 \%)$ and foot pain $(25 \%)$. The pain severity was mild in most of the women farm workers and nobody was bed ridden for back pain due to load carrying. The younger age women (25-30 years) preferred traditional way of oil massage and rest for relief from back pain and neck pain after load carrying, while older women (31-40 years) had to take rest for back pain relief. The issue of occupational health disorder associated with manual load carrying by women farm worker has to receive attention to reduce the potential health risk.
\end{abstract}

Keywords: Agriculture, Body part discomfort, Manual load carrying, Musculoskeletal disorder, Quantum of load

\section{INTRODUCTION}

In developing countries lack of mechanization in agricultural activities leads to prevalence of manual material handling tasks. With the prevalent practice in rural areas people carry loads of $30 \mathrm{~kg}$ or more on their heads, shoulders and back for long distances. Manual load carrying is very common activity performed in rural areas by women farm workers (Dufault, 1998). Baring farm machine operations women participate almost in all agricultural activity. Women participation in agriculture varies across regions, socio-cultural and economic groups as well as agro ecological and production systems. It is estimated that during peak season women work for 8 to 9 hours daily for agriculture related activities and 4 to 5 hours for household activities (Laxmi Devi, 1988). The carrying of relatively heavy loads remains a necessity for women farm workers, for various reasons; historical, political, social and economic, the rural dwellers use traditional means for carrying heavy loads such as water, fodder and cow dung daily. The lifting and carrying of loads in subsistence agriculture on small landholding are unavoidable. It is an inefficient and slow means of transport, often causing spinal injuries and other health hazards. According to Dufault (1998), often head loading is the only means of moving goods around the farm or village. Carrying heavy loads on head over long distances is physically demanding, fatigue and enhance risk of incidence of back strains, lower-back pain, fractures, chronic and debilitating back and leg related problems, damage to the knees, and other physical damage (ILO, 1989 and Haile, 1994). The emphasis of ergonomics in manual load carrying rises from the potential risks of workplace occupational musculoskeletal disorders.

According to Nag (1995), in Vietnam heavy physical work is common and loads carried on the head were found to have a detrimental effect on the vertebrae of workers (especially in the neck region). Carrying heavy loads, affects the health of women worker in different ways not restricting it to musculoskeletal disorder, e.g. prolapsed uterus (Labour Resource Centre, 1995), menstrual disorders, miscarriage, and stillbirth (NCSEW, 1998).

So the issue of occupational health disorder associated with manual load carrying by women farm worker has to receive attention to reduce the potential health risk. Mital et al.,1997 have described various existing design approaches to address the problem. These are: the physiological approach, the subjective approach, and the biomechanical approach. The subjective, physiological, and biomechanical study of manual loading carrying by women farm worker has to be done for stress estimation in different body parts especially in the spine. The spine, which is the integral as well as weakest part of the human "lifting chain" that transmits the force from the hand to the ground, is highly stressed during manual handling activities, leading to back pain 
and injury (Poulson, 1981).

India is currently undergoing a high level of economic growth and reforms. In order to maintain this level of growth, care for workers of every sector requires highest priority. India is having a work force of 430 million, out of which 241 million workers are in agriculture as compared to 33 million in industries and remaining in service/other sectors. Of these 430 million, about 140 million $(32.2 \%)$ are women workers (Census of India, 2011). In agriculture alone, $42 \%$ are women workers where they carry out various activities of agriculture, home and animal husbandry. All these activities involve more or less manual load carrying. There is no study on Indian women agricultural workers related to manual load carrying except that of Suthar and Kaushik (2011). In view of detrimental effect of manual load carrying mentioned above, the present study was undertaken to assess magnitude of load, mode and health problems in women farm workers.

\section{MATERIALS AND METHODS}

In the present study, the magnitude of load carried by women farm workers, preferred mode of load carrying and type of material carried by women farm workers and associated health problems were assessed. The study area was Thanakalan village, Kharkhoda tehsil in Sonipat district of Haryana state. In this study area, no big industrial set up exist, making agriculture as a primary occupation. Women are involved actively in farm work, animal husbandry and household work. A demographic survey of the villages was conducted with a house to house survey. A Nordiac questionnaire was prepared to assess the load carrying mode, quantum, material, health status, associated problems and anthropometric dimensions. Each women farm worker was interviewed for assessment of load carrying and health status.

Selection of women farm workers: Forty women farm workers were randomly selected with criteria of; age group of 25-40 years, at least 5 year load carrying experience, must be involved in farm work and no history of chronic illness and willingness to participate in the study. Farming is seasonal activity based on the cropping pattern; it was assumed that the average load carrying of 5 years can significantly affect the health. Women farm workers perform manual material handling associated with farming i.e. carrying of input and farm produce, also carry water, fodder and cow dung as a part of daily activity. The women below the age of 25 years and less than 5 years of experience, and women older than 40 years were excluded from the study as age mask the effect of load carrying on the musculoskeletal system. Most of the women farms workers have to work on their own farm have sufficient land to ensure appropriate work load, and nutritional security which is an important economic indicator. The majority of families were having two hectare or more of land which ensure food security and economic status (Ralevic et al., 2012).
Information regarding physical characteristics of the women farm workers i.e. age, height, weight was recorded and body mass index were calculated. Land owned by the family was also recorded from each women farm worker as given in table 1 .

Assessment of manual load carrying by women farm workers: Assessment of load carrying related stress were done by questionnaire which included (i) Physical characteristics of the women farm workers (ii) Manual load carrying (iii) Health status i.e. health history for last two weeks, last one year and in the whole lifetime. (iv) Health problems associated with load carrying (Nordiac questionnaire and with a Body diagram (Corlett and Bishop,1976)) (v) Details of any medical assistance for health problem. The questionnaire included prevailing modes of load carrying, preferred mode of load carrying (Head, shoulder, back), and quantum of load, and distance travelled with the load.

Statistical tool used for data analysis: Data analysis was performed by using the SPSS Statistical analysis tool. After stratification for age, Body mass index (BMI), experience of load carrying and quantum of load carried. Person's chi square test is applied for analyzing relationship between musculoskeletal problems, duration of pain persistence and treatment taken for pain relief.

\section{RESULTS AND DISCUSSION}

General characteristics of the women farm workers: Out of 40 participants, 20 women farm workers were from age group 25-30 years, 8 women from age group 31-40 years and 12 women from age group 36-40 years. The general characteristics of women farm workers like age, weight and height were collected for calculation of body mass index (BMI). Women farm workers are grouped according to age, BMI and experience of load carrying and quantity of load carried as given in tables 1, 2, 3 and 4. From table 2 it is clear that $70 \%$ (28 persons) participants were in "healthy category" which conform the pre selection criteria of good nutritional level of the women farm workers, and rest $17.5 \%$ "over weight", $7.5 \%$ in "grade 1 " obesity and only $5 \%$ were "underweight". Out of 40 participants, $45 \%$ had load carrying exposure of 5-10 years, $20 \%$ had 11-15 years, and 27.5\% had $16-20$ years and $7.5 \%$ more than 21 years.

Manual load carrying: In the study area farmer families own draft and milking animals. These animals are fed with green fodder in seasons and dry fodder in off seasons. Fodder carrying is an everyday activity performed by women farm workers unless they are sick or away from home. The cow dung cake is very commonly used as fuel and the cow dung cake is prepared by sun drying in open areas. There is a big bowl type container made of metal "thasla" for carrying cow dung, normally $15-20 \mathrm{~kg}$. The water carrying is also a part of their daily chore. Water carrying is a kind of social interactions at water well for many women folk. Apart from cow 
Table 1. Anthropometric details of the women farm workers.

\begin{tabular}{|c|c|c|c|c|c|c|}
\hline \multirow{2}{*}{$\begin{array}{l}\text { Age } \\
\text { group }\end{array}$} & \multirow{2}{*}{$\begin{array}{c}\text { No. of } \\
\text { women farm } \\
\text { workers }\end{array}$} & \multicolumn{5}{|c|}{ Mean anthropometric values } \\
\hline & & $\begin{array}{c}\text { Age } \\
\text { (Years) }\end{array}$ & $\begin{array}{l}\text { Weight } \\
\text { (Kg) }\end{array}$ & $\begin{array}{l}\text { Height } \\
\text { (cm) }\end{array}$ & $\begin{array}{c}\text { Body mass index } \\
\text { (BMI) }\end{array}$ & $\begin{array}{c}\text { Area of } \\
\text { cultivation } \\
\text { (Hectare) }\end{array}$ \\
\hline $25-30$ & 20 & 26.30 & 53.15 & 158.10 & 21.28 & 2.80 \\
\hline $31-35$ & 8 & 34.75 & 60.25 & 156.00 & 24.55 & 2.62 \\
\hline $36-40$ & 12 & 38.83 & 59.50 & 157.48 & 24.12 & 2.12 \\
\hline
\end{tabular}

Table 2. Age group and body mass index of the women farm workers.

\begin{tabular}{ccccc}
\hline \multirow{2}{*}{ Age Group } & \multicolumn{2}{c}{ BMI_Group } \\
\cline { 2 - 5 } & $\begin{array}{c}\text { Under weight } \\
(<\mathbf{1 8 . 5})\end{array}$ & $\begin{array}{c}\text { Healthy } \\
(\mathbf{1 8 . 5 - 2 4 . 9 )}\end{array}$ & $\begin{array}{c}\text { Over weight } \\
\mathbf{( 2 5 - 2 9 . 9 )}\end{array}$ & $\begin{array}{c}\text { Grade-1 obesity } \\
\mathbf{( 3 0 - 3 4 . 9 )}\end{array}$ \\
\hline $25-30$ & 1 & 16 & 3 & 0 \\
$31-35$ & 0 & 6 & 1 & 1 \\
$36-40$ & 1 & 6 & 3 & 2 \\
Total & $2(5 \%)$ & $28(70 \%)$ & $7(17.5 \%)$ & $3(7.5 \%)$ \\
\hline
\end{tabular}

Table 3. Age group and experience of load carrying on head.

\begin{tabular}{ccccc}
\hline \multirow{2}{*}{ Age group } & \multicolumn{4}{c}{ Experience group (in years) } \\
\cline { 2 - 5 } & $\mathbf{5 - 1 0}$ & $\mathbf{1 1 - 1 5}$ & $\mathbf{1 6 - 2 0}$ & $\mathbf{2 1 - 2 5}$ \\
\hline $25-30$ & 18 & 2 & 0 & 0 \\
$31-35$ & 0 & 4 & 4 & 0 \\
$36-40$ & 0 & 2 & 7 & 3 \\
Total & $18(45 \%)$ & $8(20 \%)$ & $11(27.5 \%)$ & $3(7.5 \%)$ \\
\hline
\end{tabular}

Table 4. Age group and quantity of load carried by women farm workers.

\begin{tabular}{ccccc}
\hline Age group & \multicolumn{3}{c}{ Quantity of load carried (in kg) } & Total \\
\cline { 2 - 5 } & $\mathbf{2 0}$ & $\mathbf{3 0}$ & $\mathbf{4 0}$ & \\
\hline $25-30$ & 12 & 7 & 1 & $20[100]$ \\
$31-35$ & 0 & 2 & 6 & $8[100]$ \\
$36-40$ & 6 & 3 & 3 & $12[100]$ \\
Total & $18(45)$ & $12(30)$ & $10(25)$ & $40[100]$ \\
\hline
\end{tabular}

[ ] shows individual row percentage;, ( ) column percentage.

dung and water carrying they carry farm inputs like seed, fertilizer and farm produce. The quantum of load carrying varies between 20-40 kg (Table 4). Women farm workers of this area generally prefer head mode of load carrying and hand barrows are not popular in this area. On an average they had to walk for 1-2 km with load every day. Fig. 1 shows the type, frequency and quantum of load carried by women farm workers. Water and cow dung weigh $20 \mathrm{~kg}$ and carried every day. Green fodder for animal feed usually weighs 30 $\mathrm{kg}$ is carried for almost 6 months (180 days) in winter and rainy season. Seed and fertilizer bags having standard weight of $40 \mathrm{~kg}$ were carried for a period of 15 days in sowing season. Harvested material weighs about $40 \mathrm{~kg}$ was carried 120 days a year depending upon the crop.

Health status: Women farm workers were interviewed for assessment of health status included past history of health problems in the last two weeks, last one year and entire life. Out of 40 women farm workers, 70 per cent women farm workers didn't have any past history of diseases and rest 30 per cent had some minor health problems. Among different health problems, musculoskeletal disorder was most common among women farm workers. Fig. 2 showed health status of women farm workers i.e. musculoskeletal disorder, cardiac and pulmonary disorder, eye and stomach problem, weakness of women farm workers in different age groups. It was observed that among different health problems, musculoskeletal disorder was dominant in all the age groups followed by weakness, eye and stomach problem.

Musculoskeletal problem as Self-reported symptoms: Musculoskeletal problem was the major health problem among the women farm workers of different age groups. It was observed that 38 out of 40 women farm workers (95\%) had musculoskeletal disorder and remaining two women farm workers did not have any musculoskeletal disorder. As carrying load by women 


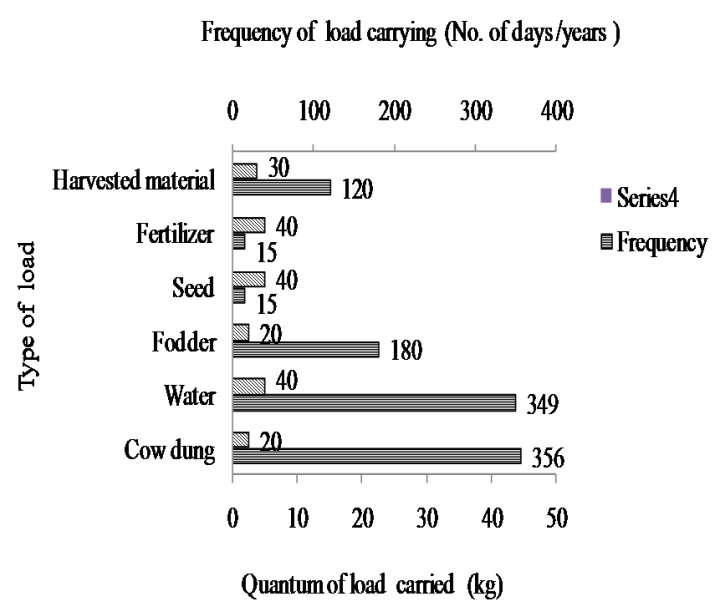

Fig.1. Type of load, frequency and quantum of load carried by women farm workers.

farm workers was an everyday activity with quantum of load varying from $10 \mathrm{~kg}$ to $40 \mathrm{~kg}$ contributed to musculoskeletal disorders.

Body part discomfort: All women farm workers in the age group of 31-35 and 36-40 years had musculoskeletal problem. 90 per cent had musculoskeletal problem in the age group of 25-30 years. This indicated that musculoskeletal problem was prevalent among all the age groups between 25-40 years. Musculoskeletal disorder included problems in muscles, bones, cartilaginous structures and joints of human body. Spine structure, muscles and bones of shoulder, hand, knee, leg, ankle and foot included in musculoskeletal structure. Pain in different body parts due to load carrying was assessed by interviewing the women farm workers with the help of questionnaire and pictorial technique (Corlett and Bishop, 1976). The pain perceived in different body parts are shown in Fig. 3.

Pain in neck: Out of all, 72.5 per cent women had pain in their neck due to carrying load on their head. This finding is similar to the finding of Suthar and Kaushik (2011) where 77 per cent of tribal women, age between 20-50 years had pain in their neck due to head load carrying on their head. With age and experience the percentage of women farm workers with neck pain increases. But statistically there is no significant difference between the three age groups (i.e. 25-30, 31-35, and 36-40 year). It is expected that load carrying experience enhanced load bearing ability of neck muscle resulting in decreased neck pain. Maloiy et al. (1986) suggested that exposure to head load carrying in young age leads to structural changes in spine that allow very heavy loads to be carried on the head with increase in age and experience. But in the present study, contrary to the above study there is a nonsignificant difference between age groups and experience regarding neck pain. This finding is similar to finding of Lloyd et al. (2010a), which also concluded that head loading is characterized by significant neck pain and long term habituation does not seems to protect against this but

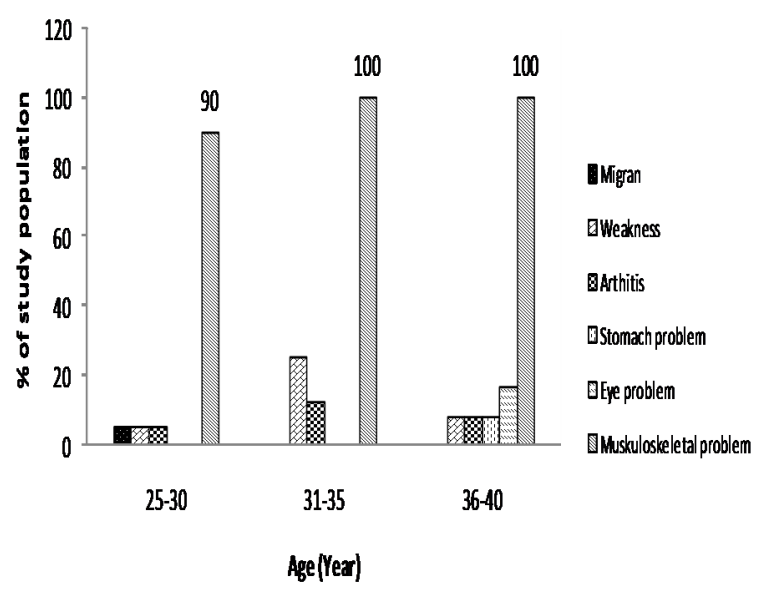

Fig.2. Different health problems among age groups of women farm workers.

habituated head loaders may have an advantage in terms of balance and stability. All women farm workers in "underweight", "overweight" and "grade-1 obesity" had neck pain whereas only 60 per cent women farm workers from healthy category had pain in their neck.

Pain in lower back: Low back pain is the most significant health problems among women workers. Pain is unlikely to arise from the intervertebral disks themselves since they do not contain nerve ending in adult (Bridger, 2008). The lower part of the back bears the weight of the upper body and any other load carried. In the present study, a total of 87.5 per cent women farm workers had problem in their lower back. The number of women farm workers with lower back pain increases from younger age group to older age group but statistically non-significant $(\mathrm{p}<0.05)$. All women farm workers in BMI group "underweight" and "grade 1obesity" and 85.7 per cent population each in "healthy" and "overweight" category had pain in lower back. In case of underweight workers there is lower prevalence of lower back pain (David et al., 2004). But in the present study the underweight category women had two to four offspring at young age of 25-27 years which may also be contributing factor to pain. In case of "overweight" and "grade-1 obesity" women farm workers excess body weight contributes to lower back pain. The result shows that more than 90 per cent women in all the experience groups of head load carrying had lower back pain. Lloyd et al. (2010 a \& b) found this method of transporting loads metabolically costly and painful. Jager et al. (1997) reported a case control study with 35 individuals who had carried load on their head (carriers) and 35 individuals who had never carried loads on their head (Non-carriers). In 31 (88.6 per cent) of the carrier, degenerative change was found in cervical spine but it was found only in 8 (22.9 per cent) in case of non-carriers. Joosab et al. (1994) reported effect of load carrying on the structural integrity of the cervical spine. In this study, the effect of head loading on the 


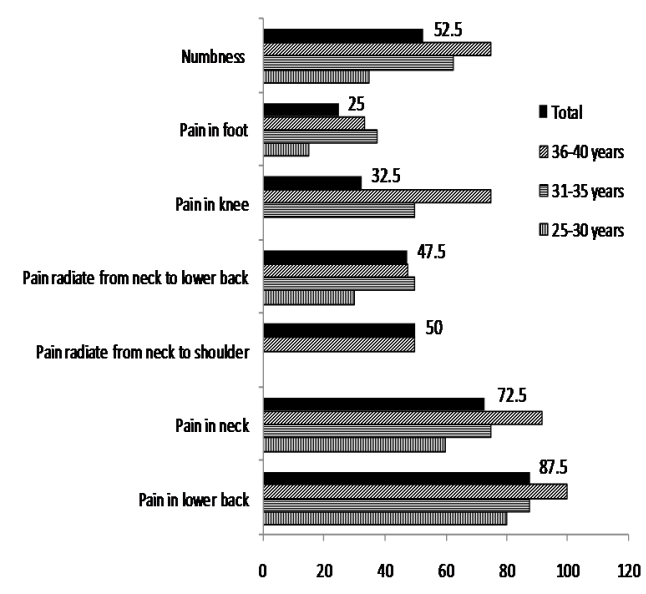

Per cent of study population

Fig. 3. Percentage of population having pain in different body parts.

pattern of spondylitis attributed to aging was examined. Load carrying seems to accentuate the straightening of the curve $(\mathrm{P}<0.001)$. The results also suggest that head loading creates a shift in the degeneration from the fifth intervertebral disc space to higher levels. It is concluded that carrying heavy loads on the head alters the pattern of degenerative changes of the cervical spine.The percentage of women farm workers carrying 20 on daily basis was more frequent those carrying $30 \mathrm{~kg}$. This is because women farm workers carry cow dung, fodder and water which weigh about $20 \mathrm{~kg}$ on daily basis and water, farm produce which weighs approximately $40 \mathrm{~kg}$ and carried only in harvesting season. But water up to $30 \mathrm{~kg}$ was carried by very small population.

Pain in foot and ankle: The pain in foot and ankle was associated with covering of long distances daily travel with head loads. A small segment i.e. 25 per cent women farm worker had reported pain in foot and ankle. Catherine et al. (2008) reported one in five people had foot pain and associated it with increased age and obesity. In the present study, also with age the foot pain increases. All women farm workers of "grade 1 obesity" had foot pain. With increase in age, experience of load carrying an increase in percentage of women having pain in foot and ankle was observed in the present study.

Pain in knee: Out of all women workers 32.5 per cent women farm workers had pain in knee which includes women farm workers in age group of 30-35 and $36-40 y e a r s$. There is no knee pain reported in younger age group 25-30 years. More than 50 per cent women from grade-1 obesity complains about pain in knee. The survey result shows that more than 50 per cent women farm workers carrying $40 \mathrm{~kg}$ had pain in knee. Similar results had been reported by Sakakibara et al. (1996), who investigated the factors associated with knee pain from residents aged over 30 years in a rural area of Japan. The prevalence of knee pain increased with age, particu- larly in women over 50s. It was significantly higher in women than in men. BMI was significantly related to knee pain in women. With reference to occupational factors, frequent heavy load lifting on the job was significantly associated with knee pain in both men and women.

Pain radiation from neck to shoulder or lower back; In 15 per cent of women farm workers pain radiate from neck to shoulder and in 47.5 per cent of women farm workers pain radiated from neck to lower back was observed. The pain radiation from neck to shoulder was mostly observed in younger age group 2530 years that is because these women farm workers has less experience of carrying load on head so usually hold the load bearing container with hand for stability which contribute to the pain in shoulder. This is similar to Thoracic outlet syndrome, caused primarily by abnormal arm posture, holding arms in unnatural positions for long periods of time. The condition occurs when a nerve that runs from the neck to the arms is compressed results in pain, numbness and weakness in the arm and hand (Richard, 2012).

During head loading muscles of neck and seven (C1-C7) top most spines in cervical region are under continuous compression. The load is gradually transferred to lower part of spine column. The inactivity of muscles retards the blood supply to the area and causes deposition of waste resulting in pain extending to lower back (Jumah and Nyame, 2004). The exertion in these body parts may lead to major musculoskeletal problems. With age and experience and quantum of load the pain radiation from neck to lower back increases.

Numbness: In present study about 52.5 per cent women farm workers showed numbness of arm and foot. A study by Sakakibara et al., 1987 concluded that working with the hands above the shoulder height is stressful. Due to static position of hands, while bearing load on head for support to the loaded material, results in fatigue in upper arm muscles and blood supply to these muscles is stopped which leads to sensory loss in arm. Neck injury may cause to feel numbness along arm or hand, while a low back injury can cause numbness or tingling down the back of leg (Frontera, 2008).

Severity of pain and duration of pain persistence and treatment for pain relief: The pain severity varied from mild (82.5 per cent women farm workers) to moderate (in 17.5 per cent women farm workers). Recovery time of mild pain is one day whereas for moderate 2-3 days. No case of severe pain was reported. Pain severity increased with age but it is independent of load carrying experience and quantum of load carried. From this result it is clear that with time carrying load on head cause a cumulative health effect on women farm workers. In younger age group 25-30 years, 90 per cent women had mild pain, 50 per cent women farm workers preferred oil massage after load carrying and remaining 50 percent women took medicine and injection for back pain but it included those who t00k medicine for pregnancy 
related back pain. In farmer family, women of age group 31-40 years carried all type of load more frequently than their younger counter parts. With age the quantum of load carried, and frequency of load carrying increases, so the pain severity enhanced from mild to moderate. Women of age group 31-40 years preferred medicine and in some cases medicine plus injection for pain relief because of higher severity of pain.

\section{Conclusion}

It was concluded that load carrying by women farm workers results in discomfort in different body parts. Lower back was the most affected portion as 87.5 per cent women farm workers complained of back pain, followed by neck pain (72.5 per cent) and knee and foot pain. The pain severity was mild in most of the women farm workers and nobody was bed ridden for back pain due to load carrying. The women (25-30 years) prefer traditional way of oil massage and rest for back and neck pain relief within reasonable time after load carrying. But older women (31-40 years) had to take medicine to recover from back pain. For women farm workers manual load carrying is part of daily chore. Carrying load on head results in significant health problems. In long run these effect will be detrimental to the health of women farm workers of India. As ergonomical considerations play a pivotal role in economic growth of a country. In view of this, there is a need to empower the women through application of ergonomics. With this motto it becomes important to educate and create awareness amongst women to carry out the various activities effectively and safely.

\section{REFERENCES}

Bridger, R.S. (2008). Introduction to Ergonomics. London, Taylor and Francis. pp. 55-60.

Catherine, L.H., Tiffany, K.G., Hylton, B.M., and Anne, W.T. (2008). Prevalence and correlates of foot pain in a populationbased study: The North West Adelaide health study. Journal of Foot and Ankle Research, I:2:doi:10.1186/1757-1146-1-2.

Census of India. 2011. retrieved from http://ncw.nic.in/pdf reports.

Corlett, E.N. and Bishop, R.P. (1976). A technique for assessing postural discomfort. Ergonomics, 19: 175-182.

David, G.B., Sam W.W and Scott, D.B. (2004). Low Back and Neck Pain: Comprehensive Diagnosis and Management, Third edition, Saunders publishers.

Dufault, A. (1998). 'Women Carrying Water: How it affects their health. Waterlines', 6: 23-25. Retrieved on 20 January, 2009 from http://www.who.int/water_sanitation_health/diseases/ wsh0302/en/index $7 . h t m l$.

Frontera, W.R. (2008). Essentials of Physical Medicine and Rehabilitation: Musculoskeletal Disorders, Pain, and Rehabilitation. 2nd ed. Philadelphia, Saunders Elsevier.

Haile, F.(1994).Occupational participation of women and health. Retrieved from http://www.popline.org/node/298511

ILO (1989). Special Protective Measures for Women and Equality of Opportunity and Treatment. Documents considered at the meeting of experts on special protective Measures for women and equality of opportunity and treatment, ILO, Geneva, Switzerland. MEPMW /1989/7, P. 87.

Jager, H.J., Gordon,H.L., Mehring, U.M., Goetz, G.F., Mathias, K.D. (1997). Degenerative change in the cervical spine and load-carrying on the head. Skeletal Radiology, 26(8):475- 481.
Joosab, M., Torode, M., Rao, P.V.(1994). Preliminary findings on the effect of load-carrying to the structural integrity of the cervical spine. Surgical and Radiologic Anatomy, 16(4):393398.

Jumah, K.B. and Nyame, P.K.(1994). Relations lower back between load carrying on the head and cervical spondylosis in Ghanaians. West Afr J. Med., 13(3): 181-182.

Labour Resource Centre. (1995). Engendering occupational health and safety. In: J Roberts Hatcher, J Kitts, L Arsenault Jones (Eds.): Gender, Health, and Sustainable Development: Perspectives from Asia and the Caribbean. Proceedings of workshops held in Singapore, 23-26 January 1995, and in Bridgetown, Barbados, 6-9 December 1994. International Development Research Centre, Ottawa, ON, Canada, pp. 69-78.

Laxmi Devi, A. (1988). Rural women: Management in farm and home, Northern Book Centre, New Delhi.

Lloyd, R., Parr, B., Davies, S. and Cooke, C. (2010b). Subjective perceptions of load carriage on the head and back in Xhosa women. Applied Ergonomics, 41: 522-529.

Lloyd, R., Parr, B., Davies, S., Partridge, T., and Cooke, C. (2010a). A comparison of the physiological consequences of head loading and back loading for African and European women. Europian Journal of Applied Physiology, 109: 607-616.

Maloiy, G.M., Heglund, N.C., Prager, L.M., Cavagna, G.A. and Taylor, C.R., (1986). Energetic costs of carrying loads: have African women discovered an economic way. $\mathrm{Na}$ ture, 319: 668-669.

Mital, A., Nicholson, A.S. and Ayoub, M.M., 1997. A Guide to Manual Materials Handling (2nd ed.), Taylor and Francis, London

Nag, N.N. (1995). Selected aspects of women's working conditions in Vietnam. From http://www.idrc.ca/ e n / e v-2 74 9 9-2 0 1-1-D O_T O P I C.h t ml.

NCSEW (National Commission on Self-Employed Women) (1998). Occupational Health Issues of Women in the Unorganized Sector: Report of the Task Force of Health. NCSEW, Bombay, India. Internet link $<\mathrm{http}: / /$ www.idrc.ca/en/ev-27499-201-1-DO_TOPIC html >

Poulson, E.1981. Back muscle strength and weight limits in lifting burdens. Spine. 61:73-75.

Ralevic, P., Patil, S.G., and Vanloon, G.W. (2012). Achieving Household Food Security: How Much Land is Required? Food Production-Approaches, Challenges and Tasks. Prof. Anna Aladjadjiyan (Ed.), ISBN: 978-953-307-887-8, InTech

Richard, M.B. (2010). Thoracic Outlet Syndrome: A Primer on Objective Methods of Diagnosis. Journal of Hand Surgery, 35(9):1539-1541.

Sakakibara, H., Masaru, M., Takaaki, K., Shin'ya, Y., Takeo, N. and Fumio, K. (1987). Relation between overhead work and complaints of pear and apple orchard workers. Ergonomics, 30(5): 805-815.

Sakakibara, H., Zhu, S.K., uruta, M.,Konda, T., Miyao, M., Yamada, S. and Hideaki, T.(1996). Knee pain and its associations with age, sex, obesity, occupation and living conditions in rural inhabitants of Japan. Environmental Health and Preventive Medicine, 1 (3):114-118.

Suthar, N. and Kaushik, V. (2011). The impact of physical work exposure on musculoskeletal problems among tribal women of Udaipur District. International $N G O$ Journal, 6 (2): 043-047. 